\title{
Para una pedagogía de la lengua oral. Los discursos orales en clase
}

\author{
Marie-Josèphe Besson y Sandra Canelas-Trevisi
}

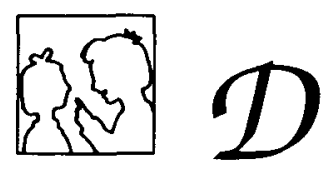

Partiendo de la idea que la lengua oral no es la pariente pobre de la lengua escrita, las autoras proponen, por una parte, que ambas modalidades se trabajen conjuntamente $y$, por otra parte, que es necesario, para trabajar de forma sistemática la lengua oral, tener en cuenta la diversidad de situaciones de producción y la diversidad de discursos beterogéneos que ellas producen. Nos lo muestran a partir de secuencias didácticas dirigidas a los alumnos de Formación Profesional.

\section{INTRODUCCION}

En los países francófonos, la mayoría de los programas de enseñanza de la lengua materna y de las lenguas extranjeras conceden, en el enunciado de principios, un lugar importante al dominio de la expresión oral. Sin embargo, estos programas son bastante vagos en cuanto a la definición de las actividades susceptibles de desarrollar las capacidades de lenguaje ${ }^{1}$ de los alumnos. Partiendo de esta constatación y del punto de vista compartido actualmente por numerosos investigadores y profesores, de que una enseñanza de la lengua oral se justifica al mismo nivel que la enseñanza de la lengua escrita, y, esto tanto para la lengua materna como para las lenguas extranjeras, hemos centrado nuestro trabajo en la descripción de actividades que pueden llevarse a cabo y que pueden responder a un objerivo de eficacia para una práctica competente de la lengua oral.

Nuestras propuestas han sido elaboradas en el marco de la formación permanente de los profesores de formación profesional (classes professionnelles), destinadas a estudiantes de comercio. Teniendo en cuenta las propuestas de investigadores interesados por el problema de la enseñanza de la lengua oral (sobre todo Roulet, 1991), hemos llevado a cabo nuestra reflexión en torno a las siguientes preguntas: ¿Qué es la lengua oral? ¿Qué lengua oral enseñar? ¿Cómo podría ser enseñada?

Los elementos de respuesta que hemos seleccionado se inspiran en las aportaciones de teóricos que trabajan en campos diferentes - psicólogos, sociólogos, lingüistas, pedagogos de la lengua ${ }^{2}$-, que han orientado nuestro trabajo. Sin embargo, es necesario precisar que los textos relativos a la lengua oral y a su enseñanza son mucho menos numerosos que los que se refieren a la lengua escrita. Nuestras suge- 
rencias se inscriben en el conjunto de investigaciones en Didáctica realizadas por el equipo de J.-P. Bronckart en la Universidad de Ginebra.

\section{¿QUÉ ES LA LENGUA ORAL?}

La observación y el análisis de numerosos documentos grabados, que son de una necesidad indispensable desde el momento en que se aborda esta problemática, permiten poner en evidencia un primer punto: la lengua oral no es una pariente pobre de la lengua escrita (Roulet, 1991). En lo que respecta al francés, la asimilación de la lengua oral al francés popular cotidiano es en la actualidad ampliamente criticada. Los juicios de valor sobre el francés oral, que mantienen que sería menos rico y menos estructurado que el francés escrito, no se justifican (Blanche-Benveniste y Jeanjean, 1987). En efecto, los documentos auténticos muestran que paralelamente a la lengua escrita, existe una lengua oral elaborada y una lengua oral menos elaborada. Lenguaje oral y lenguaje escrito son, tanto uno como otro, instrumentos privilegiados de comunicación, de interacción social y tienen que ser considerados y tratados como tales.

Trabajos relativamente recientes han enfatizado la pluralidad y la diversidad de los discursos escritos (Bronckart y cols., 1985), y han reconocido en los discursos orales esta misma pluralidad y esta misma diversidad en función de las situaciones de comunicación en las que se produce el lenguaje, y de su necesaria adaptación a las representaciones que el interlocutor se construye de dichas situaciones. Esta toma de posición teórica lleva a introducir, de manera matizada, el problema de la norma y a distinguir entre las normas descriptivas - relacionadas con los diferentes discursos producidos en situaciones de comunicación específicas -, y las normas prescriptivas - que se remiten al sistema de la lengua, que proceden de juicios de valor sobre los discursos, y que favorecen los que son arbitrariamente designados como resultado del buen uso, es decir, del lenguaje culto. A nivel de la enseñanza, y habida cuenta de los objetivos de la institución escolar, la consideración de estos dos aspectos de la norma implica un equilibrio delicado que debe buscarse y que supone dos formas de entrar en la lengua oral (como, por otra parte, en la lengua escrita), que son complemantarias: por un lado, la comunicación y, por otro, el sistema de la lengua.

\section{Las situaciones de comunicación ${ }^{3}$}

En el análisis de situaciones de comunicación, Jakobson ha sido el autor que más trabajos ha inspirado, pero también ha inspirado muchos la teoría de los actos del lenguaje (Austin,1962; Searle, 1965), siendo éstas dos concepciones disyuntas o coordinadas, según los casos. Las características reunidas en el esquema de Jakobson (emisor, receptor, referente, canal, código, mensaje) constituyen un modelo considerado como aplicable a toda forma de comunicación verbal y, debido a ese mismo hecho, hace abstracción de la diversidad de situaciones y de producciones verbales orales y escritas. Los elementos de la teoría de los actos del lenguaje han sido introducidos precisamente para rendir cuenta de dicha diversidad al hacer intervenir, por una parte, los parámetros de finalidad (expresarse para pedir algo, ordenar, comentar, etc.) y, por otra, pero sólo a veces, el parámetro de marco social en el que el lenguaje se produce. Sin embargo, otros factores diferenciales que determinan la diversidad no son tomados en cuenta. Una concepción integradora nos lleva a analizar los criterios propuestos por Jakobson en tres niveles:

- el contenido (el referente); 
- el contexto: contexto físico (emisor, receptor, espacio y tiempo) y el contexto social (lugar social y estatus social del emisor y del receptor, finalidad);

- el mensaje, o para nosotras el texto, definido como el conjunto de la producción verbal (oral o escrita) que corresponde a una sola situación de comunicación.

Las diferentes formas de contexto de las producciones verbales y en concreto, la identificación de la finalidad perseguida por las mismas, implican que se distingan los posibles casos siguientes:

a) Las producciones verbales están muy articuladas con una acción humana no verbal (a una "acción con sentido" ${ }^{4}$ identificable como tal: construir un muro, procurarse un billete de tren, etc.). En este caso, la finalidad de la producción verbal depende de la acción con sentido en curso y el lenguaje tiene un papel de «mediador» de la acción.

b) Las producciones verbales no están articuladas a una acción no verbal identificable como tal. En las conversaciones informales (que son, por otra parte, una característica propia de la especie humana), la finalidad perseguida es del orden del entendimiento o de la intercomprensión; los interlocutores negocian sus representaciones y sus conocimientos de ciertos aspectos del mundo, y dicha negociación no puede efectuarse más que por el lenguaje. En las conversaciones formales (entrevista, debate, discusión, etc.), la negociación se articula con una finalidad más o menos identificable (tomar una decisión, obtener información, comprender un problema, etc.) pero, nuevamente en este caso, la finalidad no puede ser alcanzada más que por la producción de lenguaje.

En ambos casos a) y b) que acabamos de mencionar, las producciones verbales proceden de varios interlocutores - se hablará entonces de producciones poligestionadas - y la estructura de la interacción social es la del intercambio, que es la situación típica de la lengua oral. Los intercambios dan lugar, en principio, a diálogos.

c) En un tercer caso, un solo hablante tiene la responsabilidad de la producción verbal: lleva a cabo una acción de lenguaje autónoma. Hablamos entonces de producción monogestionada. La acción de lenguaje autónoma es la situación típica de la lengua escrita. Da lugar a monólogos. Las finalidades perseguidas por la actividad de lenguaje autónoma se distribuyen en dos grandes categorías: contar y exponer (novela, editorial, artículo científico, informe, etc.). En la lengua oral, el ejemplo más frecuente es el de la exposición (curso, conferencia, discurso, etc.). La pregunta a ese nivel, y que no está resuelta a nivel científico, es saber en qué medida las actividades de lenguaje autónomas orales tienden a reproducir las características de las actividades de lenguaje autónomas escritas. También se observará que en cualquier estructura de intercambio, sobre todo en conversaciones formales, la persona que interviene puede tomar la palabra más frecuentemente y durante más tiempo. En este caso, se puede considerar que breves monólogos, presentando ciertas características de las actividades de lenguaje autónomas, se insertan en una estructura dialógica. Esta clasificación de las producciones verbales propone evidentemente una visión esquemática de las cosas: entre los diferentes tipos mencionados, las fronteras son permeables y existen situaciones intermedias.

\section{De las situaciones de comunicación a los discursos}

Tal y como lo hemos visto, toda situación de comunicación se inserta en un contexto social determinado. Dicha situación de comunicación implica un acto concreto que constituye el contexto físico; vehicula además, un cierto contenido, es decir un conjunto organizado de conocimientos. La producción oral o escrita efectuada en una u otra situación se definirá como texto. 
Si se analizan los textos producidos, constatamos que se componen de varias partes, cada una de ellas con una estructura y unas características lingüísticas diferentes. Son justamente estas estructuras del lenguaje las que se designan con el término de discurso. Caracterizadas por un plan y por unas unidades lingüísticas más o menos específicas, los discursos' son las diferentes formas de organización que se pueden observar en una lengua natural dada. Estas formas - producto de una construcción socio-histórica - pueden variar según las lenguas. Qualquier persona que produce un texto dispone, pues, de modelos de discurso (las formas de discurso usadas en su lengua y a las que ha tenido acceso) y, según la situación de comunicación en la que se encuentra, eligirá, es decir, tomará decisiones para realizar concretamente una producción verbal, en una siruación de comunicación dada, con los medios que su lengua le ofrece.

\section{El sistema de la lengua}

Las primeras investigaciones sobre la lengua oral - como ya hemos dicho, poco numerosas y relativamente recientes - se orientaron hacia la gramática y el léxico y, enfatizando las diferencias entre la lengua oral y la lengua escrita, formularon la hipótesis de que estas diferencias eran importantes. Actualmente, las investigaciones más interesantes sobre la gramática de la lengua oral (en lo que concierne al francés ${ }^{6}$ tienden a mostrar que aunque esas diferencias aparecen en el empleo de ciertas unidades, pueden, actualmente, explicarse en el marco de una misma teoria sintáctica. Según Blanche-Beneviste y Jeanjean (1986), ciertas estructuras muy corrientes en el francés hablado, pero generalmente ignoradas o tratadas de manera reduccionista o incluso condenadas en las gramáticas, no hacen más que explotar las reglas del sistema de la lengua, que son utilizadas, incluso, en francés escrito para satisfacer las exigencias de la comunicación. Fenómenos sintácticos característicos de la lengua oral, como las estructuras temáticas con anteposición (Pedro, su coche, se ha estropeado), los encadenamientos complejos de frases vinculados a las reglas del intercambio (Puedo preguntarle si tuviera usted la amabilidad de indicarme como...), las explicitaciones específicas del estatuto del enunciador (tengo a mi hermana que dió a luz ayer) - para cirar sólo estos ejemplos -, pueden explicarse mediante reglas sintácticas que son válidas tanto para la lengua oral como para la lengua escrita. En consecuencia, a nivel de la enseñanza, deberán construirse pasarelas entre lengua oral y lengua escrita, en ambos sentidos: de la lengua oral a la lengua escrita, de la lengua escrita a la lengua oral.

\section{¿QUÉ LENGUA ORAL ENSEÑAR? ¿CON QUÉ OBJETIVO?}

El objetivo a conseguir - recordemos que se trata de desarrollar la competencia de comunicación en vistas a una correcta práctica de la lengua oral - merece que precisemos lo que entendemos con esto. Esta competencia no es únicamente una capacidad para hacerse comprender y simplemente sobrevivir en la vida cotidiana. Pretende una mayor eficacia y debe permitir a un hablante producir los diferentes géneros de discurso procedentes, porque se adaptan a las situaciones de comunicación en las que se expresa. Esta competencia de comunicación hace que el interlocutor se represente las características de la situación en la cual toma la palabra, opte por una forma concreta de discurso, de manera que el destinatario lo reciba lo mejor posible y retenga, entre el abanico de posibilidades, aquellas que compiten con la eficacia deseada.

Sin embargo, esto no significa que la escuela deba preparar a los alumnos para expresarse en todas las situaciones de comunicación posibles. Esta exigencia no sería 
en absoluto realista. Hay que seleccionar pensando en aquello que les es útil a los alumnos. Según Perrenoud (1991), la escuela debería priorizar lo que él llama la comunicación "pública»: aquella que tiene lugar en el mundo del trabajo, en el mundo de las empresas, de las diversas organizaciones, de la administración, etc. cuando se trata, por ejemplo, de negociar un contrato, de discutir un alquiler, una póliza de seguros, de dar cuenta de una situación o de una experiencia personal. Las competencias relacionadas con este tipo de comunicación (saber informar, explicar, argumentar, incitar a actuar) deberían pues verse satisfechas en una pedagogía de la lengua oral. No podemos más que suscribir esta toma de posición, pero no nos adherimos a la idea de que estas competencias estén solamente asociadas a la comunicación "pública», comunicación que dicho sociólogo opone al mundo de la familia, de la vida privada, de la convivencia. Si reconocemos la necesidad de dotar a los alumnos de savoir-faire que les permitan afrontar las situaciones que engendran «la lengua oral pública», también pensamos que la vida familiar, la vida social cotidiana, el ocio, pueden ofrecer ocasiones de negociación, de argumentación, de clarificación de problemas, de estimulación a la acción que no deben descuidarse en el contexto del aprendizaje en la medida en que proporcionan modelos de discurso, sin duda alguna familiares, pero que presentan estrategias que los estudiantes podrían encontrar en las situaciones formales más complejas.

De los diversos modelos a los que puede verse abocado el que aprende una lengua, ya sea la lengua materna o una lengua extranjera, la escuela seleccionará aquellos que permitan al estudiante asumir plenamente su papel activo para intervenir en las situaciones de interacción frecuentes pero que le ocasionan dificultades: defender su punto de vista en un debate, explicar el funcionamiento de un aparato a un posible comprador o relatar un acontecimiento del que fue testigo; sin descuidar las situaciones escolares en las que el alumno debe ser capaz de hacer una breve exposición, de justificar una actitud, de verbalizar un razonamiento o de explicar unos trámites realizados. Los discursos auténticos constituirán, en primer lugar, el material de base de la enseñanza de la lengua oral. Pero difícilmente se podrá prescindir de las útiles ayudas que constituyen los modelos escolares grabados y transcritos, discursos idealizados que se basan en una ficción de la lengua oral, pero que son más accesibles para la observación y la reflexión. El problema es saber qué grado de idealización podemos aceptar, de manera que estos modelos de discurso orales no se reduzcan a los modelos de discurso escritos y no sean pues caricaturas de lenguaje oral.

\section{¿COMO SE PODRIA ENSEÑ AR LA LENGUA ORAL?}

Desde el momento en que se reconoce la importancia de la lengua oral en las relaciones sociales que condicionan la vida de rodo individuo, y que la escuela admite la necesidad de la enseñanza de dicha lengua oral - ya se trate de la lengua materna o de lenguas extranjeras -, queda por concebir una pedagogía que responda a los objetivos fijados, a los programas en vigor, a las condiciones en las cuales la enseñanza tiene lugar y - sin ser éstas últimas exigencias menores - que tomen en cuenta las necesidades de los estudiantes y sus adquisiciones.

La definición de acrividades susceptibles de favorecer el aprendizaje de la lengua oral supone que las diferentes interacciones que pueden producirse en clase estén relacionadas entre sí y que se realicen, a propósito de las situaciones, de los discursos y de los objetos de discurso, las siguientes distinciones. En primer lugar, se contrastarán los intercambios que se producen en situación directa de aquellos que se producen en situación simulada. En las situaciones directas, los interlocutores asumen el rol social que se les imparte. Los alumnos se expresan como tales, al igual que el 
maestro, cuando interviene, cuando los primeros hacen uso de la palabra para pedir al profesor informaciones sobre un trabajo que tienen que realizar, discutir una observación recibida, obtener del maestro que revise su evaluación, discutir juntos en torno a un problema de lengua, etc. En las situaciones simuladas, los interlocutores asumen momentáneamente un rol distinto del suyo en un marco social que es una reproducción de la realidad. Los juegos de roles - actividades priorizadas en la enseñanza de la lengua oral, sobre todo en el aprendizaje de lenguas extranjeras -, se articulan con las situaciones simuladas.

La segunda distinción contrastará el discurso auténtico - el que producen maestro y alumnos cuando interactúan en el marco social que constituye la escuela y que pertenece al conjunto de todos los discursos auténticos producidos en la sociedad - y el discurso ficticio, que es una representación de lo que es el lenguaje oral, como por ejemplo, los modelos de lengua oral propuestos en las grabaciones o en los manuales elaborados para el aprendizaje. Es necesario decir que los diálogos teatrales son también discursos ficticios.

La tercera distinción que debe hacerse está relacionada con el objeto de discurso que puede referirse, ya sea a las «entidades mundanas" (es decir a todo lo que puede expresarse), ya sea a la lengua misma abordada como sistema (discurso metalingüístico), ya sea desde punto de vista de su utilización en los textos (discurso metadiscursivo). Pensamos que una toma de conciencia de las distinciones subrayadas permite al maestro orientar el aprendizaje hacia tipos de prácticas diferentes y que se complementan.

\section{Las situaciones en clase}

Las actividades que proponemos han sido elaboradas en colaboración con maestros, y han encontrado una adhesión bastante general, a pesar de que no hayamos tenido la oportunidad de obtener un feed-back sobre su realización en clase. Sólo constituyen sugerencias en las cuales podrán inspirarse los maestros/profesores, pero deberán ser adaptadas a sus propias clases.

\section{Las actividades de práctica libre de la lengua oral}

Corriendo el riesgo de demostrar algo evidente, recordaremos que el principio básico de una pedagogía de la lengua oral centrada en la comunicación, plantea la necesidad de crear en la clase un ambiente y una organización de las actividades que favorezcan los intercambios maestro-alumnos y entre alumnos. Aunque es importante, no nos detendremos en esta problemática que desborda ampliamente los límites de la pedagogía de la lengua oral y que se inscribe en las opciones y en las modalidades de funcionamiento de qualquier institución escolar. Diremos sencillamente que, en este ambiente favorable, convendría dar al estudiante múltiples ocasiones para que se exprese, practique la comunicación oral y utilice con vistas al aprendizaje las situaciones de interacción directamente relacionadas con la vida escolar. Sería deseable, pues, que estas interacciones fueran valoradas no solamente en clase de lengua materna o de lenguas extranjeras, sino también en todas las asignaturas relacionadas con los diferentes ámbitos de enseñanza.

Habida cuenta de los objetivos definidos, y pesar de otorgarles un lugar fundamental en la pedagogía de la lengua oral, las actividades de práctica libre de la lengua no son muy aptas para proporcionar una enseñanza sistemática y controlada, y tampoco podrían satisfacer completamente las exigencias del aprendizaje. Esto supone que, paralelamente a dichas actividades, se realicen otras más detalladamente 
definidas, y por lo tanto más apremiantes, que tengan como finalidad la de dar al alumno, tanto a nivel discursivo como a nivel gramatical, una instrumentación realmente útil para su expresión oral.

\section{Las actividades de reflexión: escucha y comprensión}

Durante su aprendizaje, el alumno debe dotarse de una instrumentación que supone que se prevean de manera repetida en función de los documentos que serán presentados progresivamente, momentos de escucha y de observación de textos orales, es decir de grabaciones de discursos auténticos, producidos en situaciones de comunicación diversas y a partir de los cuales se llevará a cabo una primera reflexión. (Observemos que esta reflexión verbalizada constituye también un discurso que debe ser preparado).

Cuando se trabaje sobre los fenómenos que deberán identificarse durante la observación, se orientará a los alumnos mediante preguntas que permitan poner en evidencia las características de la situación (¿Quién habla? ¿A quién? ¿De qué? ¿Con qué finalidad?), así como hacia la distinción entre el diálogo (intercambio) y el monólogo (actividad de lenguaje autónoma). En función de la variedad que presenta el conjunto de textos seleccionados para la observación, haremos que los alumnos identifiquen discursos producidos para contar una historia o para relatar acontecimientos, para informar, para explicar, para clarificar algo complejo, para defender un punto de vista, una opinión, etc. Les haremos descubrir asimismo que, en muchos casos, los textos revelan discursos diferentes (textos heterogéneos) y que aquellos que corresponden a un sólo género de discurso (textos homogéneos) son menos frecuentes. Se observarán dichos discursos tanto desde el punto de vista de su planificación, como desde el punto de vista de las unidades específicas que los caracterizan. Hablaremos de ello más adelante.

Nos parece que deben hacerse dos observaciones importantes: a) Las propuestas de adaptación y de simplificación de los elementos teóricos tomados en consideración son impuestas por las restricciones de la situación escolar que implica que se lleven a cabo transformaciones didácticas a partir del saber teórico. Estas transposiciones comportan un doble riesgo: por una parte, el de seleccionar un número demasiado numeroso de nociones, incluso inútiles, para la enseñanza y presentarlas a los alumnos de manera demasiado compleja; por otra parte, el de simplificar excesivamente los elementos teóricos de tal forma que el recurso a un saber solicitado para una mayor eficacia de la enseñanza sea inoperante . b) Nos parece indispensable que la reflexión sobre los textos orales y sus condiciones de producción se lleven a cabo conjuntamente con la reflexión sobre los textos escritos. El intercambio entre ambas modalidades discursivas suscita comparaciones que una pedagogía eficaz no puede pasar por alto.

\section{Las actividades de producción oral}

Tal y como han sido descritas anteriormente, las actividades de reflexión consisten esencialmente en una sensibilización, por parte de los aprendices, a propósito de la diversidad de situaciones y de géneros de discurso relacionados con las mismas. Como lo hemos mencionado anteriormente, en las actividades de producción propiamente dichas se tratará de poner en evidencia, por una parte, ciertos procedimientos relacionados con la planificación de los textos y, por otra, las unidades espe- 
cíficas requeridas para que los alumnos saquen partido de esta toma de conciencia en el momento en que deberán tomar la palabra.

En esta etapa preparatoria de la actividad de producción se plantea el problema, bastante crucial, de los modelos de discurso que se adoptarán. En efecto, nos parece ilusorio que el maestro pueda trabajar constantemente con discursos auténti$\cos$, que no son necesariamente buenos documentos pedagógicos, tanto más que los discursos orales son más difíciles de observar que los discursos escritos. Para que los alumnos puedan circunscribir mejor las dificultades, admitimos el recurso a una lengua oral idealizada - grabaciones orales o transcritas - elaborada para el aprendizaje que permita ejercitar de forma más sistemática ciertos fenómenos. Nuestras sugerencias deben situarse precisamente en esta óptica. Éstas se centran, por un lado, en los intercambios (diálogos) y, por otro, en actividades de lenguaje autónomas (monólogos).

\section{Los intercambios: los juegos de roles}

Si bien el juego de roles es la actividad-típica de la enseñanza de lenguas extranjeras, pensamos que puede ser también útil a la pedagogía de la lengua oral de la lengua materna, si se proponen a los alumnos situaciones suficientemente estimulantes orientadas hacia acciones de lenguaje variadas, y, al mismo tiempo, se les ofrece la posibilidad de perfeccionar aquellos discursos que todavía no dominan suficientemente.

Como hemos dicho, los juegos de roles se basan en la simulación de una situación de comunicación en la que los interlocutores se encuentran cara a cara. En consecuencia, en la presentación del ejercicio tendrán que precisarse los elementos más importantes de la situación: a) el contexto social y esencialmente el estatus social de los interlocutores (se encuentran o no en la misma posición de igualdad social: comparemos un diálogo entre dos compañeros de clase y un diálogo entre un empleado y el director de la fábrica, por no citar más que estos dos ejemplos); y b) la(s) finalidad(es) perseguida(s), que constituyen el hilo conductor del intercambio.

Señalaremos a los alumnos que deberán interpretar los roles que les son asignados en la situación; les recordaremos que los interlocutores construyen su discurso de manera anclada en la situación y conjuntamente, teniendo en cuenta lo que dice uno y otro y ejerciendo mutua influencia sobre sus respectivas palabras. Al principio de la actividad, la consigna que será formulada minuciosamente, deberá permitir a los alumnos saber exactamente qué deben hacer, habida cuenta que la preparación de la producción les habrá llevado a comprender el cómo y el por qué de la actividad que se les ha pedido. Esta preparación los habrá llevado igualmente a poner en orden los elementos de contenido que necesitarán en su producción. Los ejemplos de discursos ficticios presentados a continuación pueden ayudar al maestro a disponer de algunos puntos de referencia útiles para preparar sus intervenciones y seleccionar algunas pistas de evaluación. No constituyen, de modo alguno, modelos para reproducir tal cual.

\section{Situación}

Durante el descanso del mediodía, Jorge y Enrique, que son colegas de trabajo, comen en la misma mesa. Empiezan a intercambiar algunas palabras y pasan a hablar del trabajo de la mujer. No tienen la misma oponión sobre este tema. Cada uno da la suya y buscan hacer valer sus argumentos.

Jorge: Comes regularmente en la cafetería desde hace algunos días. ¿Tu mujer está enferma?

Enrique: No, trabaja. Ha encontrado un puesto de secretaria en un bufete de abogados. 
J: ¿Desde hace tiempo?

E: $\quad$ Apenas una semana.

J: ¿Y te acostumbras?

E: Más o menos... Hace falta tiempo... Encuentro que los niños son aún pequeños y esto complica la vida en casa. Pero mi mujer parece contenta. Y además, tendremos un poco más de dinero para llegar a fin de mes.

J: A mí no me gustaría en absoluto que mi mujer trabajara. En mi opinión, una mujer que tiene hijos debe ocuparse de ellos y tiene ya bastante trabajo con ello.

E: $\quad$ Es fácil de decir cuando se puede vivir de un solo sueldo.

J: $\quad$ Es verdad que a veces nos cuesta anudar los dos cabos. Pero a nuestros hijos les gusta encontrar a su madre cuando llegan de la escuela.

E: Y tu mujer, ¿qué piensa ella?

El Sr. X se presenta en una agencia de viajes y pide a la empleada que le organice las vacaciones explicándole lo que desea. Ésta le sugiere un lugar, describe ciertas características y justifica las propuestas hechas. Contesta a otras preguntas complementarias de su cliente y le invita a que se tome un tiempo de reflexión antes de decidirse.

Cliente: Buenos días

Empleada: Buenos días. ¿En qué puedo servirle?

C: $\quad$ Mire. Me gustaría pasar tres semanas de vacaciones a orillas sel mar. Preferentemente en Cerdeña, o en Sicilia.

E: ¿En qué temporada?

C: $\quad$ A partir de la segunda quincena de septiembre.

E: De acuerdo... Bueno, le aconsejo Cerdeña. Las posibilidades de estancia son muy agradables y hay bastantes ventajas en esa época.

C: Sí..

E: $\quad$ Por ejemplo, en la costa noroeste (le enseña un mapa), las playas son estupendas Es ideal para unas vacaciones tranquilas porque hay menos turistas en esa época.

C: $\quad$ Pero yo quisiera también moverme un poco, visitar la isla.

E: $\quad$ Es totalmente posible. Pueden hacerse muchas excursiones.

C: ¿Yel precio?

E: $\quad$ Todo depende de la categoría del hotel que usted escoja.

C: $\quad$ Seremos dos y nos gustaría un hotel confortable, con vistas al mar y media pensión.

E: $\quad$ En nuestro catálogo tenemos tres proyectos diferentes (le tiende el catálogo) Mírelos tranquilamente. Estoy a su disposición si necesita más información. Pero no tarde mucho en decidirse.

C: $\quad$ Se lo agradezco. Me lo pensaré y muy pronto le daré una respuesta.

Estos dos diálogos, corrientes en la vida cotidiana, presentan finalidades generales muy diferentes. El primero, que es un intercambio informal, tiende hacia la argumentación. El segundo, que es una forma de negociación y tiene un carácter formal, es más bien del orden de la información-explicación. El maestro podrá seleccionar algunos aspectos para que los alumnos se fijen en ellos:

- la fluidez y la coherencia de las réplicas;

- la forma en que se encadenan los enunciados y las unidades (conectores, organizadores) que marcan los encadenamientos;

- la manera que tiene el emisor de hacerse suyo lo que dice (marcas de afirmación de sí mismo, de evaluación, de modalización). Estas marcas aparecen más claramente en el diálogo a) que en el b). Cuando los alumnos hayan adquirido una cierta soltura en la práctica de estos diálogos familiares, se podrán introducir juegos de roles más directamente relacionados con situaciones que impliquen discursos convencionalizados que obedecen a restricciones sociales más imperativas y más numerosas?.

\section{Las actividades de lenguaje autónomas}

Como hemos visto anteriormente, en ciertas situaciones, el hablante toma la palabra y la mantiene un cierto tiempo, asumiendo él solo la gestión del texto oral 
que produce. (Recordemos el ejemplo del conferenciante que da una exposición, el de un orador, el que sea, pronunciando un discurso) (8). Hemos observado también que en los diálogos, ciertas réplicas de los interlocutores suponen intervenciones más extensas que toman la forma de breves monólogos. El hablante debe asumir su gestión interna. Dependiendo de discursos diferentes (narrativo, descriptivo, informativo, injuntivo, explicativo, argumentativo), dichos monólogos quedan condicionados por el intercambio en curso.

En las interacciones propuestas a los alumnos, éstos encuentran a menudo dificultades en la producción y en la gestión de estas réplicas más largas. Las actividades que sugerimos, y de las cuales proponemos algunos ejemplos a continuación, consisten en aislar, para un estudio más puntual y más sistemático, ciertos segmentos del discurso susceptibles de constituir un intercambio, y una práctica.

\section{Presentación de la situación y consigna}

Un turista extranjero le para en el Puente del Mont-Blanc, del lado del lago, para preguntarle cómo se va a la estación.

Usted le da las indicaciones necesarias.

No está muy lejos. Va usted en la buena dirección. Al final del puente, siga derecho la calle del Mont-Blanc hasta la plaza Cornavin. Ya verá, hay una gran plaza con muchos autobuses, cerca de una gran iglesia. La estación está justo delante de usted. Si quiere entrar directamente a la estación, tome el paso subterráneo.

b. Usted acompaña a un niño a su casa, quien casi acaba de tener un grave accidente delante de usted y que no está más que ligeramente herido.

Le explica a su madre lo que ha sucedido.

Hace un momento, su hijo se encontraba en el cruce delante del paso cebra y esperaba que el semáforo se pusiera verde para los peatones. De golpe, uno de sus amigos se le acercó y... no sé porque razón, lo empujó hacia la calzada y luego huyó. En ese momento llegaba un coche. Afortunadamente tenía buenos frenos. Tiene solamente algunos rasguños.

c. En el curso de una conversación con su jefe, discuten sobre su futuro en la empresa. En un momento dado, usted aborda el tema de su sueldo y le da algunos argumentos para convencerle de que le conceda un aumento.

Me gustaría mucho quedarme en su empresa porque el trabajo y el ambiente me gustan mucho. Pero quisiera un aumento de sueldo. Ya hace cinco años que estoy en su empresa. Creo que mi jefe de servicio está contento conmigo. Y además... la vida está cara...

De nuevo, los breves monólogos propuestos no constituirían modelos para reproducir. Repetimos que se trata simplemente de dar al maestro una idea de las direcciones que pueden tomar en este tipo de producciones y de definir algunas exigencias para los alumnos, que podrían tomarse en cuenta en la evaluación de dichas producciones.

\section{Intercambios $y$ actividades de lenguaje autónomas}

Los ejercicios que acabamos de presentar (juegos de roles, breves monólogos) pueden ser propuestos tanto para la enseñanza de la lengua materna como para la de la lengua extranjera, siempre y cuando se parta de situaciones que respondan a las capacidades de expresión, y que aseguren a los alumnos el dominio efectivo de la lengua. Ni decir tiene que, en lengua materna, podrán practicarse actividades de lenguaje oral más complejas.

Las actividades que describiremos suscintamente a continuación han sido extraidas de una secuencia elaborada en torno a una documentación escrita, dirigida a todos los ciudadanos suizos, con motivo de una votación sobre una iniciativa popu- 
lar que pedía la prohibición de experimentaciones con los animales. Se trata, teniendo en cuenta que es un tema que se presta bien a ello, de cambiar ciertas condiciones de producción, para obtener discursos orales en los que los alumnos deberán tener en cuenta ciertas restricciones en el curso de los intercambios y de las actividades de lenguaje autónomas en las que participarán.

En un primer momento, la lectura comprensiva del documento, en el cual encontramos tanto textos provenientes de los instigadores de la iniciativa como de aquellos que la combaten, permite a los alumnos la representación de un contenido que no les es necesariamente familiar. En segundo lugar, precediendo a la producción oral propiamente dicha, se llevará a cabo una reflexión para que los alumnos pongan en evidencia las características de la situación propuesta y de los discursos que deberán producir.

\section{Intercambio conversacional informal}

Imaginemos la siguiente situación.Dos amigos se encuentran por casualidad en el bar. Felipe espera que abran el local habilitado para votar mientras toma un café. Sergio entra y de repente ve a Felipe y se reune con él. Felipe dice a Sergio que se prepara para ir a votar y la conversación se orienta hacia la iniciativa contra la experimentación animal. Ambos amigos tienen opiniones distintas e intentan convencerse mutuamente.

Sergio: ¡Hola Felipe!

Felipe: ¡Hombre, Sergio! ¿Qué haces por aquí?

Sergio: Mira, ya ves. Pasaba por el barrio... tenía un poco de sed... ¿y tú?

Felipe: Yo voy a ir a votar. Como todavía no está abierto... He venido a tomar un café mientras espero.

Sergio: ¡Uh! ¡Esto me hace pensar que yo también debo ir! ¡Pero ya no sé muy bien por qué votamos!

Felipe: Pero sí, es a causa de la iniciativa contra los experimentos con animales. ¡Ya se ha hablado demasiado!

Sergio: Ah, sí, sí... Tienes razón. ¿Tú estás a favor?

Felipe: ¡Más bien!, Sabes, a mí me gustan mucho los animales y encuentro desagradable hacerles sufrir para nada.

Sergio: No es para nada ya que sirve para encontrar medicinas contra las enfermedades.

Felipe: De acuerdo, pero q(uizás) se hacen demasiadas experiencias que no son siempre útiles...

Sergio: Sí, pero hacen falta permisos (para hacer esas experiencias). No se pueden hacer de cualquier manera.

Felipe: ¡Eso es lo que dicen! ¡Pero a mí me gustaría estar seguro que esto sirve únicamente a la medicina!

Sergio: En todo caso, a mí también me gustan los animales, pero no me gustaría que interrumpieran las investigaciones. Si hubieras contraído el Sida, estarías contento de que se hicieran todas las investigaciones posibles para (encontrar como) curarte, aunque esto haga sufrir a los bichos.

Felipe: Bueno, bueno, ya veo que no votaremos lo mismo.

Sergio: Desde luego que no.

Felipe: ¡Hale, tengo que irme! A pesar de todo, estoy contento de haberte encontrado.

Sergio: ¡Yo también! ¡Hasta pronto!

\section{Intercambio conversacional formal}

Imaginemos la situación siguiente. En una entrevista radial, un periodista entrevista a un representante del comité de iniciativa a favor de la reducción de la experimentación animal. Respondiendo a las preguntas, éste defiende su punto de vista procurando convencer a los oyentes para que voten sí a la iniciativa.

El periodista: Buenos días Señor $X$.

Señor X: Buenos días Señor J. 
El periodista: Señor $\mathrm{X}$, usted es miembro del Comité a favor de la iniciativa contra la experimentación animal. El próximo fin de semana usted votará sí a la iniciativa. ¿Podría decimos en primer lugar y brevemente en qué consiste esta iniciativa?

Señor X: Con mucho gusto. Nuestra iniciativa, como su nombre lo indica, no se opone a la experimentación animal, pero quiere que esta experimentación se reduzca. Esta precisión me parece importante ya que nuestros adversarios dicen que estamos en contra de la experimentación animal y esto no es exacto.

El periodista: ¿Puede precisar qué es lo que entiende usted por ello?

Señor X: Bueno. Encontramos que los experimentos son muy numerosos y que no todos son útiles. Por ejemplo, los que se hacen para la fabricación de cosméticos, de detergentes y de otros productos nocivos deberían prohibirse completamente.

El periodista: Le entiendo. ¿Pero ustedes se oponen también a ciertas experimentaciones en el marco de la investigación médica?

Señor X: Efectivamente. En algunos casos, incluso para la investigación médica, deberían encontrarse otros medios diferentes al de la experimentación animal.

El periodista: ¿No tiene usted miedo que el progreso científico se vea frenado por la iniciativa?

Señor X: ¡ ¡No, en absoluto! Nuevamente, no se trata de obstaculizar la investigación sino de orientarla hacia otras direcciones encontrando soluciones que permitieran evitar que se utilice sistemáticamente la experimentación animal.

El periodista: Para concluir, ya que el tiempo pasa, ¿qué dirá usted a nuestros oyentes?

Señor X: Y Y Y $\quad$ bien, les diré: « ¿Voten sí a la iniciativa! Votando sí, protegen a los animales sin poner en peligro la salud del hombre».

\section{Actividad de lenguaje autónoma}

Imaginemos la situación siguiente. En una emisión de TV organizada en el marco de las votaciones, un periodista invita a dos personalidades ( $\mathrm{P}$ y $\mathrm{C}$ ) encargadas de presentar y de defender sus respectivos puntos de vista para convencer al público presente en la emisión.

$P$ está a favor de la iniciativa. Toma la palabra en primer lugar. C que está en contra, hablará después. Ambos se dirigen al mismo destinatario. Cada uno tiene el mismo tiempo para tomar la palabra. Después de las dos intervenciones, el público podrá preguntar o discutir loque se habrá dicho.

El emisor $\mathrm{P}$ tiene la palabra.

La iniciativa a favor de la reducción de la experimentación animal no es el proyecto de aquellos que querrían más a los animales que a los hombres, como así lo pretenden a menudo nuestros adversarios.

Está a favor de la protección de los animales, esto es verdad, pero no se trata en absoluto de salvarlos en detrimento de la salud y de la vida de los humanos.

La prueba es que nuestra iniciativa admite perfectamente los experimentos que permiten salvar vidas humanas.

Sin embargo, pensamos que muchos de los experimentos que se hacen son inútiles y que la ley debería prohibirlos.

No obstante, la ley no es lo suficientemente precisa para prever todos los casos.

Es por ello que presentamos otro proyecto que será sometido al voto.

Son ciertamente numerosos los que tienen un animal en su casa, al que le tienen cariño y seguramente no soportarían verle sufrir cruel e inútilmente.

Todos aquellos a quienes les gustan los animales, piensen en ellos cuando vayan a votar.

El emisor C tiene la palabra.

A mí me gustan mucho los animales. Incluso tengo en casa dos perros y tres gatos que no quisiera hacer sufrir inútilmente.

Sin embargo, digo no a la iniciativa para la reducción de la experimentación animal. En efecto. ¡Cómo justificar una ley que obligaría a renunciar a los experimentos indispensables para la salud y para la vida humana! Nuestros adversarios nos dicen que es necesario evitar los experimentos inútiles. ¡De acuerdo! ¿Pero se puede saber cuáles son inútiles antes de 
haberlos llevado a cabo? En Suiza, existen leyes en favor de la protección de los animales que son muy razonables. La nueva ley que propone la iniciativa va demasiado lejos y retrasaría la investigación y el progreso científico.

¿Se puede defender un proyecto tal en un momento en el que se desarrollan horribles enfermedades sin que sepamos aún cómo curarlas?

Antes de ir a votar, reflexionen bien sobre las consecuencias de su voto.

Rechacen la iniciativa y los peligros que podrían ocasionar a la salud del hombre... y de los animales.

d. Se puede modificar la situación que acabamos de proponer haciéndola evolucionar hacia el debate. El periodista de la emisión lleva a los interlocutores a un debate interactivo en el cual son alternativamente emisor y destinatario.

P. Entrando en este debate, me gustaría decir de entrada que nuestra iniciativa no siempre se ha entendido bien. A menudo la han deformado y aprovecho la ocasión que se me ofrece aquí para explicar nuestras intenciones, para precisar ciertos puntos. En efecto, nuestros adversarios hablan de la iniciativa contra la experimentación animal. Sin embargo, su título exacto es «Limitemos estrictamente la experimentación animal». A pesar de todo, hay un matiz.

C. Permítame interrumpirle ya que no puedo dejar pasar por alto eso. Sí, ustedes limitan, pero estos límites son tan numerosos, tan restringidos que desanimarían a los científicos para que continuaran sus investigaciones. Mejor dicho, que en el fondo, Ustedes desean suprimir la experimentación animal.

P. iEn absoluto! Además lo hemos dicho. Pero usted admitirá conmigo que nos podemos preguntar sobre la necesidad de ciertas experimentaciones animales. Muchas son completamente inútiles.

C. Pero usted se reserva decir precisamente cuáles. Los detergentes, los productos nocivos, de acuerdo... ¡Pero las que conciernen a la investigación médica! ¿Cuáles son inútiles? ¿Puede usted informarnos concretamente? Etc.

Nos parece importante subrayar una vez más que, habida cuenta de su carácter ficticio, los discursos propuestos a modo de ejemplo, no son la reproducción exacta de discursos auténticos. En las producciones de los alumnos, ciertas características de la lengua oral, forzosamente neutralizadas en nuestros ejemplos, aparecen espontáneamente. Evitaremos condenarlas en la medida en que cumplen con la finalidad que se quiere conseguir a través del discurso y no proceden de una mala representación de la situación.

\section{A MODO DE CONCLUSION}

Las orientaciones didácticas que sugerimos provienen de una concepción del aprendizaje de la lengua oral que se funda en los siguientes principios:

- abordar la lengua oral en tanto que medio de comunicación al mismo nivel que la lengua escrita;

- favorecer la toma de conciencia de la importancia que tiene la lengua oral en la sociedad en general, pero también en el marco restringido del medio escolar (situaciones relacionadas con la vida de la clase, situaciones específicas de enseñanzaaprendizaje);

- llevar a cabo el aprendizaje de la lengua oral en correlación con el de la lengua escrita para poner en evidencia lo que es común a ambas modalidades de discurso y lo que hace su especificidad;

- favorecer el dominio de ciertos medios de expresión que contribuyen a la eficacia del discurso que tiene que producirse. Estos principios implican el recurso a teorías de orientaciones diferentes extraídas, por una parte, del estudio de los discursos y, por otra parte, del estudio de la sintaxis, a las que la didáctica debería reconocer una compatibilidad y una complementariedad, habida cuenta de los objetivos y de las necesidades del aprendizaje. 


\section{Notas}

1. NdT. El francés dintingue entre «linguistique» y «langagier». Nosostras traducimos, el primero por lingüístico/a, mientras que el segundo por «de lenguaje» (por ejemplo: «capacités langagières" por "capacidades de lenguaje»).

2. Véase Wirthner, M.; Martin, D. y Perrenoud, P. (1991).

3. El análisis presentado en 1.1 y en 1.2 se basa en un documento elaborado por J.-P. Bronckart para la formación permanente de maestros/profesores, documento que todavía no ha sido publicado.

4. NdT. Traducimos «action sensée» por «acción con sentido", término que ya ha sido utilizado en otras traducciones (por ejemplo, en Bronckart (1992), traducido por Mariana Miras).

5. Para un análisis más detallado a propósito de los discursos, véase Bronckart $(1985,1992)$.

6. Estas investigaciones han sido realizadas en colaboración con el GARS (Groupe aixois de recherches en syntaxe, Grupo de Aix-en-Provence de investigaciones en sintaxis).

7. Se observará en relación a este propósito, que las marcas lingüísticas de organización y de conexión tienden a ser menos numerosas y menos variadas en la lengua oral, la entonación sobre todo permite reemplazar las unidades lingüísticas.

8. A propósito de la conferencia en situación escolar, véase Giger-Plazaola en este mismo monográfico.

\section{Referencias}

Austin, J.L. (1979) Quand dire, c'est faire, París, Seuil

BAKHTINE, M. (1984) Esthétique de la création verbale, París, Gallimard

BL.ANCHE-BENVENISTE, C. (1983), «L'importance du 'français parlé' pour la description du 'français tout court'”, en Gars, S, pp. $23-45$

Blanche-Benveniste, C. y JeAnJean, C. (1987) Le fransais parlé. Transcription et édition, París, Didier Erudition

BESSON, M.-J. y cols. (1979) Maîtrise du français, Neuchâtel, IRDP, Commission romande des moyens d'enseignement

Bronckart, J.-P., Bain, D.; Schneuwliy, B.; Davaud, C. y Pasquier, A. (1985) Le fonctionnement des discours, Neuchâtel-París, Delachaux y Niestlé

BronCKART, J.-P. (1992) «El discurso como acción. Por un nuevo paradigma psicolingüistico», Anuario de psicologia, 54 , pp. $3-48$

Dabene, L.; Cicurel, F.; Lauga-Hamid, M.-C. y Foerster, C. (1990) Variations et rituels en classe de langue, París, Hatier

JAKOBSON, R. (1963) Essais de linguistique générale, París, Editions de Minuit

MOIRAND, S. (1990) Une grammaire des textes et des dialogues, París, Hachette

RosaT, M.-C. (1991) «A propos de réalisations orale et écrite d'un texte argumentatif», en Etudes de linguistique appliquée, 81, pp. 119-130

Rosat, M.-C. (1993) «Réfléchir pour la classe sur la diversité des oraux», en Le français aujourd'bui, 101, pp. $70-76$

Roulet, E. (1985) «Pragmatique et pédagogie. Apprendre à communiquer, c'est apprendre à négocier", en Langues et linguistique, 11, pp. 37-57

Roulet, E. (1991) «La pédagogie de l'oral en question(s)», en WIrThNer, M.; Martin, D. y PerreNoun, P. (Eds.), Parole étouffeé, parole libérée, Neuchâtel-París, Delachaux y Niestlé, pp. 41-54

ROULET, E. y cols. (1985) L'articulation du discours en français contemporain, Berna, Lang

SEARLE, J.R. (1972) Les actes de langage: essai de pbilosopbie du langage, París, Hermann

Wirthner M.; MARTin D. y PerRenoud P. (Eds.) (1991) Parole étouffée, parole libérée. Fondements et limites d'une pédagogie de l'oral, Neuchâtel-París, Delachaux y Niestlé. 


\section{3}

\section{Para una pedagogía de la lengua oral. Los discursos orales en clase Marie-Josèphe Besson y Sandra Canelas-Trevisi CL\&E, 1994, 23, pp. 29-43}

Resumen: La necesidad generalmente admitida de una enseñanza de la lengua oral orienta el debate pedagógico alrededor de las siguientes cuestiones: ¿Qué es la lengua oral? ¿Qué lengua oral enseñar? ¿Cómo puede ser enseñada? Los elementos de la respuesta que intentamos aportar nos conducen a no considerar la lengua oral como la pariente pobre de la lengua escrita y a tomar en cuenta para el aprendizaje, la pluralidad y la diversidad de discursos orales en función de las situaciones de comunicación en las que son producidos. De ahí surge la nécesidad, a nivel didáctico, de abordar la lengua oral, al mismo nivel que la lengua escrita, en tanto que medio de comunicación; de hacer tomar conciencia a los que aprenden de las características de las situaciones y de los discursos orales; de acostumbrarlos a la elección pertinente y a la práctica correcta de discursos diferentes. Las actividades sugeridas ponen el énfais en los géneros de discurso que los estudiantes deberán producir para responder a las exigencias de la sociedad.

Agradecimientos: Traducción de Mercè Pujol y Mercè Cartié. Nuestro agradecimiento a Ricardo Castelao por las correcciones efectuadas al presente manuscrito.

Datos sobre el autor: Marie-Josèphe Besson, encargada de investigaciones en Didáctica de las Lenguas en la Facultad de Psicología y Ciencias de la Educación de la Universidad de Ginebra, es co-autora de una metodología para la enseñanza de la lengua materna, que es utilizada en las escuelas primarias de la Suiza de habla francesa. Colabora en la formación permanente de maestros y profesores.

Sandra Canelas-Trevisi, ayudante en Didáctica de las Lenguas en la Facultad de Psicología y de Ciencias de la Educación de la Universidad de Ginebra, está llevando a cabo su tesis doctoral sobre la problemática de la realización discursiva de los contenidos de la enseñanza a diferentes niveles del funcionamiento didáctico. Colabora en la formación permanente de maestros y profesores.

Dirección: Universidad de Ginebra, Facultad de Psicología y Ciencias de la Educación, Unidad de Didáctica de las lenguas, 9, Rte de Drize, $\mathrm{CH}$ - 1227 Ginebra (Suiza).

C PERMISOS PARA CITAR O REPRODUCIR EN OTRAS FUENTES: Se pueden citar libremente hasta 500 palabras. Para reproducir una porción de texto mayor, figuras o ilustraciones, se deberá pedir permiso por escrito a la revista, especificando el uso al que se destina el texto. En todos los casos, se deberá citar el copyright de $C L \& E$. En el caso de artículos o textos que hayan sido a su vez reproducidos en $C L \& E$ los interesados deberán dirigirse tanto a los detentadores del copyright original como a $C L \& E$, en el caso de que se quiera hacer uso de la traducción. FOTOCOPIAS: Para todo lo relacionado con el uso mediante fotocopia del material de esta revista, deberán dirigirse a: CEDRO, C/ José Marañón, 10,3. Izda. Tel. 5941575 . Fax 4453567 